\title{
Operating Leverage and the Interaction between Abandonment Options and Exotic Hedging*
}

\author{
Kit Pong WONG ${ }^{\dagger}$ \\ University of Hong Kong
}

July 2004

This paper examines the interaction between operational and financial hedging in the context of the competitive firm under output price uncertainty. The firm is endowed with an abandonment option in that its production decision is made after the true realization of the random output price has been observed. If the realized output price is less than its marginal cost, the firm optimally exercises its abandonment option and ceases from production. Otherwise, the firm lets its abandonment option extinguish and produces at its capacity. The existence of the abandonment option is shown to induce the firm to opt for a concave payoff risk-sharing rule that can be perfectly replicated by writing call options with a single strike price set equal to the marginal cost. We derive necessary and sufficient conditions that ensure a positive (negative) effect of operational hedging via the abandonment option on the firm's optimal operating leverage. In contrast, we show that the effect of financial hedging via customized exotic derivatives on the firm's optimal operating leverage is unambiguously positive. These results suggest that the interaction between abandonment options and exotic hedging is multi-dimensional and deserves further scrutiny.

JEL classification: D21; D81; G31

Keywords: Operating leverage; Abandonment options; Exotic hedging

\footnotetext{
*I gratefully acknowledge financial support from a grant provided by the University Grants Committee of the Hong Kong Special Administrative Region, China (Project No. AoE/H-05/99). I would like to thank Mamouda Mbemap (the editor) and Jin Zhang (the referee) for their helpful comments and suggestions. The usual disclaimer applies.

${ }^{\dagger}$ Correspondence to: Kit Pong Wong, School of Economics and Finance, University of Hong Kong, Pokfulam Road, Hong Kong. Tel.: (852) 2859-1044, fax: (852) 2548-1152, e-mail: kpwong@econ.hku.hk (K. P. Wong).
} 
Interaction between Abandonment Options and Exotic Hedging

\title{
OPERATING LEVERAGE AND THE INTERACTION BETWEEN ABANDONMENT OPTIONS AND EXOTIC HEDGING
}

\author{
KIT PONG WONG \\ School of Economics and Finance, University of Hong Kong \\ Pokfulam Road, Hong Kong, China \\ kpwong@econ.hku.hk
}

\begin{abstract}
This paper examines the interaction between operational and financial hedging in the context of the competitive firm under output price uncertainty. The firm is endowed with an abandonment option in that its production decision is made after the true realization of the random output price has been observed. If the realized output price is less than its marginal cost, the firm optimally exercises its abandonment option and ceases from production. Otherwise, the firm lets its abandonment option extinguish and produces at its capacity. The existence of the abandonment option is shown to induce the firm to opt for a concave payoff risk-sharing rule that can be perfectly replicated by writing call options with a single strike price set equal to the marginal cost. We derive necessary and sufficient conditions that ensure a positive (negative) effect of operational hedging via the abandonment option on the firm's optimal operating leverage. In contrast, we show that the effect of financial hedging via customized exotic derivatives on the firm's optimal operating leverage is unambiguously positive. These results suggest that the interaction between abandonment options and exotic hedging is multi-dimensional and deserves further scrutiny.
\end{abstract}

Keywords: Operating leverage; abandonment options; exotic hedging.

\section{Introduction}

The concept of real options is the analysis of investment decisions taking into account the ability to revise future operating decisions (McDonald, 2003). Examples of real options include, but are not limited to, options to abandon, options to defer, options to expand, and options to contract. In a survey conducted by Triantis and Borison (2001), managers reveal that they use real options as an analytical tool, as a language and framing device for investment problems, and as an organizational process. 
The purpose of this paper is to study the interaction between operational hedging via real options and financial hedging via customized exotic derivatives. To this end, we incorporate abandonment options into Sandmo's (1971) model of the competitive firm under output price uncertainty. ${ }^{1}$ Succinctly, the firm is endowed with an abandonment option in that the firm makes its production decision after observing the true realization of the random output price. When the realized output price is less than its marginal cost, the firm optimally exercises its abandonment option and ceases from production. The firm lets its abandonment option extinguish, thereby producing at the maximum level allowed by its production capacity, only when the realized output price exceeds its marginal cost. The $e x$ post exercising of the abandonment option as such convexifies the firm's ex ante profit with respect to the random output price.

We endogenize the firm's operating leverage and its production capacity as functions of the investment in fixed costs engaged prior to the resolution of the output price uncertainty. By definition, operating leverage measures the percentage change in net operating income for a given percentage change in sales. Since operating leverage increases as fixed costs rise and as variable costs fall (Ross et al., 2005, p. 327), we specify the firm's operating leverage in a reduced form by a constant marginal cost that decreases with the investment in fixed costs. Production capacity, on the other hand, is defined by a maximum level of output up to which the firm can produce. This maximum level of output increases with the investment in fixed costs.

To examine how the firm's operating leverage, and thus its investment in fixed costs, is affected by the interaction between operational and financial hedging, we allow the firm to avail itself of fairly priced exotic derivatives for hedging purposes. We refer to this as "exotic hedging." We show that the firm optimally tailors its customized exotic derivative contract in a way that the hedged profit is stabilized at the expected level, thereby eliminating all

\footnotetext{
${ }^{1}$ The extant literature on the theory of the competitive firm typically assumes that the firm makes its production decision prior to the resolution of output price uncertainty (see, e.g., Batra and Ullah, 1974; Chavas, 1985; Wong, 1996; to name just a few). That means, even when the realized output price is lower than its marginal cost, the firm would not optimally cease from production. Alternatively put, the firm as such possesses no options to abandon.
} 
output price risk. ${ }^{2}$ We also show that this optimal exotic derivative contract can be perfectly replicated by writing call options with a single strike price set equal to the marginal cost.

The effect of operational hedging via the abandonment option on the firm's optimal operating leverage is a priori indeterminate. It depends on the elasticity of the operating leverage and that of the production capacity with respect to the investment in fixed costs. The presence of the abandonment option induces the firm to increase (decrease) its optimal operating leverage if the production capacity is sufficiently more (not too) elastic relative to the operating leverage with respect to the investment in fixed costs. In contrast, the effect of financial hedging via customized exotic derivatives on the firm's optimal operating leverage is unambiguously positive. These findings show that the interaction between abandonment options and exotic hedging is multi-dimensional and depends on how we scrutinize it.

Robichek and Van Horne (1967) are the first to point out the importance of abandonment options to capital budgeting. McDonald and Siegel (1985) examine how the presence of abandonment options affects the valuation of firms. Myers and Majd (1990) propose a procedure that links a project's economic life to its performance taking into account its abandonment value. This paper is closest in the spirit of Ware and Winter (1988), Moschini and Lapan (1992), and Wong (2004). Ware and Winter (1988) consider the competitive exporting firm under exchange rate uncertainty such that the firm possesses the ex post flexibility in selling to either the domestic market or a foreign market. ${ }^{3}$ The firm's $e x$ ante profit denominated in the domestic currency is shown to be convex in the random exchange rate due to the ex post exercising of the option to export. While the strike price of the exporting option in Ware and Winter (1988) is exogenously given, the strike price of the abandonment option in this paper is endogenously determined. This explains why the presence of the real option has an ambiguous effect on investment in our setting but always enhances production in Ware and Winter (1988).

Moschini and Lapan (1992) study the competitive firm under output price uncertainty

\footnotetext{
${ }^{2}$ This is analogous to a well-known result in the insurance literature that a risk-averse individual fully insures at an actuarially fair price (Mossin, 1968).

${ }^{3}$ See also Eldor and Zilcha (1987), Broll and Wahl (1997), and Wong (2001, 2003) for the study of the behavior of export-flexible firms under exchange rate uncertainty.
} 
such that the firm possesses the ex post flexibility in adjusting its production decision. Our model is certainly a special case of theirs as Moschini and Lapan (1992) allow continuous adjustments to output while we only allow a binary choice of output. To achieve better hedging performance, Moschini and Lapan (1992) show that the production-flexible firm opts for more complicated hedging strategies involving the use of straddles. ${ }^{4}$

In a similar vein, Wong (2004) examines the behavior of the competitive firm under output price uncertainty in the presence of an abandonment option, where the firm is restricted to use forward/futures contracts for hedging purposes. The major concern of Wong's (2004) paper is on the robustness of the celebrated separation and full-hedging theorems emanated from the hedging literature (Danthine, 1978; Holthausen, 1979; and Feder et al., 1980). The separation theorem states that the production decision of the competitive firm is affected neither by the risk attitude of the firm nor by the incidence of the output price uncertainty should the firm have access to a forward/futures market. The full-hedging theorem states that the firm should completely eliminate its output price risk exposure by adopting a full-hedge if the forward/futures market is unbiased. This paper, in contrast, focuses on how the interaction between operational and financial hedging affects the firm's optimal operating leverage. In addition, unlike Wong (2004) that exclusively looks at forward/futures hedging, we impose no restriction on the set of hedging instruments available to the firm. Thus, our consideration of exotic hedging gives rise to a first-best risk-sharing rule catering to the firm's hedging need.

The rest of this paper is organized as follows. Section 2 delineates our model of the competitive firm under output price uncertainty wherein an abandonment option is incorporated. To hedge against the output price risk, the firm can trade customized exotic derivatives. Section 3 characterizes the firm's optimal operating leverage and exotic derivative contract. Section 4 examines the effect of operational hedging via the abandonment option on the firm's optimal operating leverage. Section 5 goes on to examine the effect of financial hedging via customized exotic derivatives on the firm's optimal operating leverage.

\footnotetext{
${ }^{4}$ See Chang and Wong (2003) for sufficient conditions under which the use of straddles is optimal for cross-hedging purposes.
} 
Interaction between Abandonment Options and Exotic Hedging

Section 6 concludes. All proofs of propositions are relegated to the Appendix.

\section{The Model}

Consider a variant model of the competitive firm under output price uncertainty $\grave{a} l a$ Sandmo (1971). There is one period with three dates (indexed by $t=0,1$, and 2 ). The riskless rate of interest is known and constant for the period. As such, we suppress the interest factors to simplify notation in that all cash flows are compounded to their future values at $t=2$.

At $t=0$, the firm chooses its investment in fixed costs, $i$, that determines the operating leverage as well as the production capacity proffered to the firm. Succinctly, the operating leverage is expressed in a reduced form by a constant marginal cost, $c(i)$, where $c^{\prime}(i) \leq 0$ and $c^{\prime \prime}(i) \geq 0$. Given this specification, an increase in $i$ is tantamount to an increase in the operating leverage (Ross et al., 2005, p. 327). The production capacity, on the other hand, is defined by a maximum level of output, $\bar{q}(i)$, up to which the firm can produce, where $\bar{q}^{\prime}(i) \geq 0$ and $\bar{q}^{\prime \prime}(i) \leq 0$.

The output price uncertainty is modeled by a random variable, $\tilde{p}$, which denotes the prevailing output price at $t=2 .{ }^{5}$ This random variable is distributed according to a probability density function, $g(p)$, and a cumulated distribution function, $G(p)$, over support $[\underline{p}, \bar{p}]$, where $0<\underline{p}<\bar{p}<\infty$. Let $\mathrm{E}(\cdot), \mathrm{E}(\cdot \mid \cdot)$, and $\operatorname{Cov}(\cdot, \cdot)$ be the unconditional expectation operator, the conditional expectation operator, and the covariance operator with respect to $g(p)$, respectively.

To hedge against its exposure to the output price risk, the firm avails itself of customized exotic derivatives at $t=0$. The payoff of an exotic derivative contract at $t=2$ is delineated by a function, $\theta(p)$, whose functional form is chosen by the firm at $t=0$. To focus on the hedging motive, vis-à-vis the speculative motive, of the firm, we assume that the contract is fairly priced in that $\mathrm{E}[\theta(\tilde{p})]=0$. That is, we interpret $\theta(p)$ as net of the price of the

\footnotetext{
${ }^{5}$ Throughout the paper, random variables have a tilde $(\sim)$ while their realizations do not.
} 
contract.

At $t=1$, the firm privately observes the true realization of the prevailing output price at $t=2$. Based upon this observation, the firm makes its production decision according to the operating leverage and production capacity that have already been set up at $t=0$.

Figure 1 depicts how the sequence of events unfolds in the model.

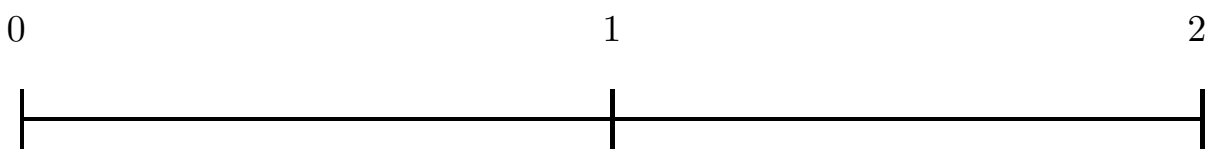

The firm makes its investment and hedging decisions.
The firm privately observes the true realization of the output price at $t=2$ and makes its production decision.
The firm sells its output and settles its hedge position.

Fig. 1. Time line.

The firm is an expected utility maximizer and possesses a von Neumann-Morgenstern utility function, $u(\pi)$, defined over its profit at $t=2, \pi$. The firm is risk averse so that $u^{\prime}(\pi)>0$ and $u^{\prime \prime}(\pi)<0 .{ }^{6}$ The sequential decision problems of the firm can be solved by using backward induction.

At $t=1$, after privately observing the true realization of the prevailing output price at $t=2$, the firm makes its production decision under certainty:

$$
\max _{0 \leq q \leq \bar{q}(i)} u\{[p-c(i)] q-i+\theta(p)\},
$$

\footnotetext{
${ }^{6}$ For privately held, owner-managed firms, risk-averse behavior prevails. Even for publicly listed firms, managerial risk aversion (Stulz, 1984), corporate taxes (Smith and Stulz, 1985), costs of financial distress (Smith and Stulz, 1985), and capital market imperfections (Stulz, 1990; and Froot et al., 1993) all imply a concave objective function for firms, thereby justifying the use of risk aversion as an approximation. See Tufano (1996) for evidence that managerial risk aversion is a rationale for corporate risk management in the gold mining industry.
} 
where $i$ and $\theta(p)$ are taken as given because they have been chosen at $t=0$. Since the firm's profit function is linear in $q$ as evident from program (1), the optimal production decision is characterized by a bang-bang solution: If $p>c(i)$, the firm produces at the maximum level, $\bar{q}(i)$; if $p<c(i)$, the firm ceases from production. ${ }^{7}$ The firm as such possesses an abandonment option that is exercised whenever the realized output price is below the marginal cost. We can compactly write the firm's random profit at $t=2$ as

$$
\pi(p)=\max [p-c(i), 0] \bar{q}(i)-i+\theta(p) .
$$

Thus, the ex post exercising of the abandonment option convexifies the firm's ex ante profit with respect to the random output price.

Anticipating its optimal production decision at $t=1$, the firm chooses its investment in fixed costs, $i$, and a fairly priced exotic derivative contract, $\theta(p)$, at $t=0$ so as to maximize the expected utility of its random profit at $t=2$ :

$$
\max _{i, \theta(p)} \mathrm{E}\{u[\pi(\tilde{p})]\} \quad \text { s.t. } \mathrm{E}[\theta(\tilde{p})]=0
$$

where $\pi(p)$ is defined in equation (2).

\section{Optimal Investment and Hedging Decisions}

The first-order conditions for program (3) are given by

$$
\begin{aligned}
& -\int_{\underline{p}}^{c\left(i^{*}\right)} u^{\prime}\left[\pi^{*}(p)\right] g(p) \mathrm{d} p \\
& \quad+\int_{c\left(i^{*}\right)}^{\bar{p}} u^{\prime}\left[\pi^{*}(p)\right]\left\{\left[p-c\left(i^{*}\right)\right] \bar{q}^{\prime}\left(i^{*}\right)-c^{\prime}\left(i^{*}\right) \bar{q}\left(i^{*}\right)-1\right\} g(p) \mathrm{d} p=0, \\
& u^{\prime}\left[\pi^{*}(p)\right]-\lambda^{*}=0 \text { for all } p \in[\underline{p}, \bar{p}],
\end{aligned}
$$

\footnotetext{
${ }^{7}$ The firm is indifferent between producing at its maximum capacity or abandoning its production when $p=c(i)$, which occurs with probability zero.
} 
where equation (4) follows from Leibniz's rule, $\lambda$ is the Lagrange multiplier, and an asterisk $\left.{ }^{*}\right)$ indicates an optimal level. ${ }^{8}$

Proposition 1. If the competitive firm possessing the abandonment option is allowed to use fairly priced exotic derivatives for hedging purposes, the firm's optimal operating leverage, thereby its optimal investment in fixed costs, $i^{*}$, solves

$$
\int_{c\left(i^{*}\right)}^{\bar{p}}\left\{\left[p-c\left(i^{*}\right)\right] \bar{q}^{\prime}\left(i^{*}\right)-c^{\prime}\left(i^{*}\right) \bar{q}\left(i^{*}\right)\right\} g(p) \mathrm{d} p-1=0
$$

and the optimal exotic derivative contract, $\theta^{*}(p)$, is given by

$$
\theta^{*}(p)=\left\{\nu^{*}-\max \left[p-c\left(i^{*}\right), 0\right]\right\} \bar{q}\left(i^{*}\right)
$$

where $\nu^{*}=\mathrm{E}\left\{\max \left[\tilde{p}-c\left(i^{*}\right), 0\right]\right\}$.

To see the intuition of Proposition 1, we write equation (2) as

$$
\begin{aligned}
\pi(p)=\mathrm{E}\{\max & {[\tilde{p}-c(i), 0]\} \bar{q}(i)-i } \\
& +\theta(p)-\{\mathrm{E}\{\max [\tilde{p}-c(i), 0]\}-\max [p-c(i), 0]\}\} \bar{q}(i) .
\end{aligned}
$$

It is evident from equation (8) that the firm's investment in fixed costs, $i$, affects its output price risk exposure through the last term on the right-hand side of equation (8). Suppose that the firm ignores the marginal risk effect of its investment in fixed costs on this term. The optimal operating leverage, and thus the optimal investment in fixed costs, $i^{*}$, is then chosen to maximize $\mathrm{E}\{\max [\tilde{p}-c(i), 0]\} \bar{q}(i)-i$, thereby yielding equation (6). When $i=i^{*}$ and $\theta(p)=\theta^{*}(p)$, the final term on the right-hand side of equation (8) vanishes and thus can be ignored. Hence, $i^{*}$ and $\theta^{*}(p)$ are indeed the optimal solution to the firm's ex ante decision problem.

\footnotetext{
${ }^{8}$ The second-order conditions for program (3) are satisfied given risk aversion and the assumed properties of $c(i)$ and $\bar{q}(i)$.
} 
Two remarks are in order. First, the firm tailors the exotic derivative contract, $\theta(p)$, in a way that its hedged profit at $t=2$ is stabilized at the expected level, thereby eliminating all output price risk. Second, according to equation (7), the optimal exotic derivative contract can be easily replicated by writing $\bar{q}\left(i^{*}\right)$ units of the call option contracts with the strike price set equal to $c\left(i^{*}\right)$. Due to the fact that the firm's unhedged profit at $t=2$ is piece-wise linear with a kink at $c(i)$, one single option contract suffices to perfectly track this payoff structure. $^{9}$

\section{The Effect of Abandonment Options on Operating Leverage}

To examine the effect of operational hedging via the abandonment option on the firm's optimal operating leverage, we consider the hypothetical case wherein the abandonment option is absent. That is, the firm is obliged to produce at its maximum capacity irrespective of the true realization of the prevailing output price at $t=2$ privately observed by the firm at $t=1$. In this case, the firm's random profit at $t=2$ is given by

$$
\bar{\pi}(p)=[p-c(i)] \bar{q}(i)-i+\theta(p) .
$$

At $t=0$, the firm chooses its investment in fixed costs, $i$, and a fairly priced exotic derivative contract, $\theta(p)$, so as to maximize the expected utility of its random profit at $t=2$ :

$$
\max _{i, \theta(p)} \mathrm{E}\{u[\bar{\pi}(\tilde{p})]\} \quad \text { s.t. } \mathrm{E}[\theta(\tilde{p})]=0
$$

where $\bar{\pi}(p)$ is defined in equation (9). The first-order conditions for program (10) are given by

$$
\mathrm{E}\left\{u^{\prime}\left[\bar{\pi}^{0}(\tilde{p})\right]\left\{\left[\tilde{p}-c\left(i^{0}\right)\right] \bar{q}^{\prime}\left(i^{0}\right)-c^{\prime}\left(i^{0}\right) \bar{q}\left(i^{0}\right)-1\right\}\right\}=0,
$$

\footnotetext{
${ }^{9}$ In general, Carr and Madan (2001) show that it is always feasible to construct a portfolio of options with a continuum of strike prices that perfectly tracks any payoff structure of a firm under a single source of uncertainty. See also Wong (2003).
} 


$$
u^{\prime}\left[\bar{\pi}^{0}(p)\right]-\mu^{0}=0 \text { for all } p \in[\underline{p}, \bar{p}]
$$

where $\mu$ is the Lagrange multiplier, and a nought $\left({ }^{0}\right)$ indicates an optimal level. ${ }^{10}$

Proposition 2. If the competitive firm possessing no abandonment options is allowed to use fairly priced exotic derivatives for hedging purposes, the firm's optimal operating leverage, thereby its optimal investment in fixed costs, $i^{0}$, solves

$$
\left[\mathrm{E}(\tilde{p})-c\left(i^{0}\right)\right] \bar{q}^{\prime}\left(i^{0}\right)-c^{\prime}\left(i^{0}\right) \bar{q}\left(i^{0}\right)-1=0
$$

and the optimal exotic derivative contract, $\theta^{0}(p)$, is given by

$$
\theta^{0}(p)=[\mathrm{E}(\tilde{p})-p] \bar{q}\left(i^{0}\right)
$$

To see the intuition of Proposition 2, we recast equation (9) as

$$
\bar{\pi}(p)=[\mathrm{E}(\tilde{p})-c(i)] \bar{q}(i)-i+\theta(p)+[p-\mathrm{E}(\tilde{p})] \bar{q}(i) .
$$

Inspection of equation (15) reveals that the firm could have completely eliminated its output price risk exposure had it chosen $\theta(p)=[\mathrm{E}(\tilde{p})-p] \bar{q}(i)$, which can be perfectly replicated by a full-hedge via shorting $\bar{q}(i)$ units of the unbiased futures contracts. Alternatively put, the degree of output price risk exposure to be assumed by the firm should be totally unrelated to its investment decision. The optimal investment in fixed costs, $i^{0}$, is then chosen to maximize $[\mathrm{E}(\tilde{p})-c(i)] \bar{q}(i)-i$. Equations (13) and (14) are simply the celebrated separation and full-hedging theorems of Danthine (1978), Holthausen (1979), and Feder et al. (1980).

Proposition 3. When the competitive firm is allowed to use fairly priced exotic derivatives for hedging purposes, the presence of the abandonment option induces the firm to raise (lower) its optimal operating leverage, thereby its investment in fixed costs, if, and only if,

$$
\left\{c\left(i^{0}\right)-E\left[\tilde{p} \mid \tilde{p}<c\left(i^{0}\right)\right]\right\} \bar{q}^{\prime}\left(i^{0}\right)+c^{\prime}\left(i^{0}\right) \bar{q}\left(i^{0}\right)>(<) 0,
$$

\footnotetext{
${ }^{10}$ The second-order conditions for program (10) are satisfied given risk aversion and the assumed properties of $c(i)$ and $\bar{q}(i)$.
} 
where $i^{0}$ is the optimal investment in fixed costs in the absence of the abandonment option.

The sign of the left-hand side of condition (16) is a priori indeterminate and can either be positive or be negative. To see this, suppose first that $c^{\prime}(i) \equiv 0$. The left-hand side of condition (16) is unambiguously positive because $c\left(i^{0}\right)>E\left[\tilde{p} \mid \tilde{p}<c\left(i^{0}\right)\right]$ and $\bar{q}^{\prime}(i) \geq 0$. Thus, we have $i^{*}>i^{0}$. On the other hand, suppose that $\bar{q}^{\prime}(i) \equiv 0$. In this case, the left-hand side of condition (16) becomes unambiguously negative since $c^{\prime}(i) \leq 0$. It then follows that $i^{*}<i^{0}$.

To interpret condition (16), we consider the case wherein $c^{\prime}\left(i^{0}\right)<0$ and $\bar{q}^{\prime}\left(i^{0}\right)>0 .{ }^{11}$ Dividing both sides of condition $(16)$ by $-c^{\prime}\left(i^{0}\right) \bar{q}^{\prime}\left(i^{0}\right) i^{0}$ and rearranging terms yields ${ }^{12}$

$$
-\frac{c\left(i^{0}\right) / i^{0}}{c^{\prime}\left(i^{0}\right)}-\frac{\bar{q}\left(i^{0}\right) / i^{0}}{\bar{q}^{\prime}\left(i^{0}\right)}>(<)-\frac{E\left[\tilde{p} \mid \tilde{p}<c\left(i^{0}\right)\right]}{c^{\prime}\left(i^{0}\right) i^{0}} .
$$

Note that $-c\left(i^{0}\right) / i^{0} c^{\prime}\left(i^{0}\right)$ is the reciprocal of the elasticity of the operating leverage with respect to the investment in fixed costs. Likewise, $\bar{q}\left(i^{0}\right) / i^{0} \bar{q}^{\prime}\left(i^{0}\right)$ is the reciprocal of the elasticity of the production capacity with respect to the investment in fixed costs. Condition (17) says that the presence of the abandonment option induces the firm to increase (decrease) its optimal operating leverage if the production capacity is sufficiently more (not too) elastic relative to the operating leverage with respect to the investment in fixed costs.

The intuition of Proposition 3 is as follows. Equations (2) and (9) imply that

$$
\pi(p)=\bar{\pi}(p)+\max [c(i)-p, 0] \bar{q}(i)
$$

In the absence of the abandonment option, it follows from Proposition 2 that the optimal investment in fixed costs, $i^{0}$, is chosen to maximize $[\mathrm{E}(\tilde{p})-c(i)] \bar{q}(i)-i$. However, if the firm possesses the abandonment option, there is an additional positive term on the right-hand

\footnotetext{
${ }^{11}$ The case wherein $c^{\prime}\left(i^{0}\right)=0$ or $\bar{q}^{\prime}\left(i^{0}\right)=0$ has been discussed before.

${ }^{12}$ Since $\underline{p}<E\left[\tilde{p} \mid \tilde{p}<c\left(i^{0}\right)\right]<c\left(i^{0}\right)$, we have$$
0<-\frac{\underline{p}}{c^{\prime}\left(i^{0}\right) i^{0}}<-\frac{E\left[\tilde{p} \mid \tilde{p}<c\left(i^{0}\right)\right]}{c^{\prime}\left(i^{0}\right) i^{0}}<-\frac{c\left(i^{0}\right) / i^{0}}{c^{\prime}\left(i^{0}\right)} .
$$ 
side of equation (18), $\max [c(i)-p, 0] \bar{q}(i)$, which depends on $i$. Since $\bar{q}^{\prime}(i) \geq 0$, for $c(i)$ fixed, to increase this additional gain due to the abandonment option, the firm is induced to invest beyond $i^{0}$. On the other hand, since $c^{\prime}(i) \leq 0$, for $\bar{q}(i)$ fixed, to increase this additional gain due to the abandonment option, the firm is induced to invest below $i^{0}$. In general, when both $c(i)$ and $\bar{q}(i)$ vary with $i$, the above two effects act in the opposite directions. Hence, it is a priori indeterminate whether the firm invests more or less than $i^{0}$ so as to take advantage of the presence of the abandonment option.

\section{The Effect of Exotic Hedging on Operating Leverage}

Now, we want to examine the effect of financial hedging via customized exotic derivatives on the firm's optimal operating leverage. To this end, we consider the hypothetical case wherein the firm is banned from engaging in risk management. That is, we set $\theta(p) \equiv 0$ and thus the firm's random profit at $t=2$ is given by

$$
\hat{\pi}(p)=\max [p-c(i), 0] \bar{q}(i)-i .
$$

Anticipating its optimal production decision at $t=1$, the firm chooses its investment in fixed costs, $i$, at $t=0$ so as to maximize the expected utility of its random profit at $t=2$ :

$$
\max _{i} \mathrm{E}\{u[\hat{\pi}(p)]\}
$$

where $\hat{\pi}(p)$ is defined in equation (19). The first-order condition for program (20) is given by

$$
\begin{aligned}
& -\int_{\underline{p}}^{c\left(i^{\diamond}\right)} u^{\prime}\left[\hat{\pi}^{\diamond}(p)\right] g(p) \mathrm{d} p \\
& \quad+\int_{c\left(i^{\diamond}\right)}^{\bar{p}} u^{\prime}\left[\hat{\pi}^{\diamond}(p)\right]\left\{\left[p-c\left(i^{\diamond}\right)\right] \bar{q}^{\prime}\left(i^{\diamond}\right)-c^{\prime}\left(i^{\diamond}\right) \bar{q}\left(i^{\diamond}\right)-1\right\} g(p) \mathrm{d} p=0,
\end{aligned}
$$

where equation (21) follows from Leibniz's rule and a diamond $\left(^{\diamond}\right)$ indicates an optimal 
level. ${ }^{13}$

Proposition 4. If the competitive firm possessing the abandonment option is banned from engaging in risk management, its optimal operating leverage depends on its risk preferences as well as on the underlying output price uncertainty. Furthermore, introducing customized exotic derivatives to the firm for hedging purposes induces the firm to raise its optimal operating leverage, thereby its investment in fixed costs. That is, $i^{\diamond}<i^{*}$.

To see the intuition of Proposition 4, we write equation (19) as

$$
\begin{aligned}
\bar{\pi}(p)=\mathrm{E}\{\max & {[\tilde{p}-c(i), 0]\} \bar{q}(i)-i } \\
+ & \{\max [p-c(i), 0]-\mathrm{E}\{\max [\tilde{p}-c(i), 0]\}\} \bar{q}(i) .
\end{aligned}
$$

The last term on the right-hand side of equation (22) is random and has mean zero. Since the firm is banned from engaging in risk management, this random noise term can only be controlled by varying $i$. Given risk aversion, it is thus optimal for the firm to invest less than $i^{*}$, a result in line with that of Sandmo (1971).

\section{Conclusions}

In this paper, we have examined the interaction between operational and financial hedging in the context of the competitive firm under output price uncertainty à la Sandmo (1971). The firm's operating leverage and its production capacity are endogenously determined by the investment in fixed costs engaged prior to the resolution of the output price uncertainty. The firm is endowed with an abandonment option in that the firm makes its production decision after observing the true realization of the random output price. The firm optimally exercises the abandonment option when the realized output price is less than its marginal

\footnotetext{
${ }^{13}$ The second-order condition for program (20) is satisfied given risk aversion and the assumed properties of $c(i)$ and $\bar{q}(i)$.
} 
cost. In this case, no production is undertaken. On the other hand, when the realized output price exceeds its marginal cost, the firm optimally lets its abandonment option extinguish and produces at the maximum level allowed by its production capacity. The ex post exercising of the abandonment option as such convexifies the firm's ex ante profit with respect to the random output price.

We have shown that the convexity due to the presence of the abandonment option induces the firm to opt for a concave payoff risk-sharing rule that can be perfectly replicated by writing call options with a single strike price set equal to the marginal cost. We

have derived necessary and sufficient conditions that ensure a positive (negative) effect of operational hedging via the abandonment option on the firm's optimal operating leverage. In contrast, we have shown that the effect of financial hedging via customized exotic derivatives on the firm's optimal operating leverage is unambiguously positive. These findings thus suggest that the interaction between abandonment options and exotic hedging is multi-dimensional and depends on how we scrutinize it.

While we have focused on abandonment options, the analysis of this paper should be applicable to other real options embedded in investment decisions. Given the prevalence of real options, how operational and financial hedging are interrelated warrants more studies. We leave this challenge for future research.

\section{Acknowledgments}

I gratefully acknowledge financial support from a grant provided by the University Grants Committee of the Hong Kong Special Administrative Region, China (Project No. AoE/H05/99). I would like to thank Mamouda Mbemap (the editor) and Jin Zhang (the referee) for their helpful comments and suggestions. The usual disclaimer applies. 


\section{Appendix}

\section{A. Proof of Proposition 1}

It is evident from equation (5) that $\max \left[p-c\left(i^{*}\right), 0\right] \bar{q}\left(i^{*}\right)-i^{*}+\theta^{*}(p)=u^{\prime-1}\left(\lambda^{*}\right)$ for all $p \in[\underline{p}, \bar{p}]$, where $u^{\prime-1}\left(\lambda^{*}\right)$ is a constant. It then follows from $\mathrm{E}\left[\theta^{*}(\tilde{p})\right]=0$ that $u^{\prime-1}\left(\lambda^{*}\right)=$ $\nu^{*} \bar{q}\left(i^{*}\right)-i^{*}$, thereby implying equation (7). Substituting equation (7) into equation (4) yields equation (6).

\section{B. Proof of Proposition 2}

It is evident from equation (12) that $\left[p-c\left(i^{0}\right), 0\right] \bar{q}\left(i^{0}\right)-i^{0}+\theta^{0}(p)=u^{\prime-1}\left(\mu^{0}\right)$ for all $p \in[\underline{p}, \bar{p}]$, where $u^{\prime-1}\left(\mu^{0}\right)$ is a constant. It then follows from $\mathrm{E}\left[\theta^{0}(\tilde{p})\right]=0$ that $u^{\prime-1}\left(\mu^{0}\right)=$ $\left[\mathrm{E}(\tilde{p})-c\left(i^{0}\right)\right] \bar{q}\left(i^{0}\right)-i^{0}$, thereby implying equation (14). Substituting equation (12) into equation (11) yields equation (13).

\section{Proof of Proposition 3}

Evaluating the left-hand side of equation (6) at $i^{0}$ yields

$$
\int_{c\left(i^{0}\right)}^{\bar{p}}\left\{\left[p-c\left(i^{0}\right)\right] \bar{q}^{\prime}\left(i^{0}\right)-c^{\prime}\left(i^{0}\right) \bar{q}\left(i^{0}\right)\right\} g(p) \mathrm{d} p-1 .
$$

Using equation (13), the above expression reduces to

$$
\int_{\underline{p}}^{c\left(i^{0}\right)}\left\{\left[c\left(i^{0}\right)-p\right] \bar{q}^{\prime}\left(i^{0}\right)+c^{\prime}\left(i^{0}\right) \bar{q}\left(i^{0}\right)\right\} g(p) \mathrm{d} p,
$$

which can be stated as

$$
\left\{\left\{c\left(i^{0}\right)-E\left[\tilde{p} \mid \tilde{p}<c\left(i^{0}\right)\right]\right\} \bar{q}^{\prime}\left(i^{0}\right)+c^{\prime}\left(i^{0}\right) \bar{q}\left(i^{0}\right)\right\} G\left[c\left(i^{0}\right)\right] .
$$


Since $G\left[c\left(i^{0}\right)\right]>0$, it then follows from the above expression, equation (6), and the secondorder conditions for program (3) that condition (16) is the necessary and sufficient condition for $i^{*}>(<) i^{0}$.

\section{Proof of Proposition 4}

Rewrite equation (21) as

$$
\begin{aligned}
& \mathrm{E}\left\{u^{\prime}\left[\hat{\pi}^{\diamond}(\tilde{p})\right]\right\}\left\{\int_{c\left(i^{\diamond}\right)}^{\bar{p}}\left\{\left[p-c\left(i^{\diamond}\right)\right] \bar{q}^{\prime}\left(i^{\diamond}\right)-c^{\prime}\left(i^{\diamond}\right) \bar{q}\left(i^{\diamond}\right)\right\} g(p) \mathrm{d} p-1\right\} \\
& =\int_{c\left(i^{\diamond}\right)}^{\bar{p}}\left\{\mathrm{E}\left\{u^{\prime}\left[\hat{\pi}^{\diamond}(\tilde{p})\right]\right\}-u^{\prime}\left[\hat{\pi}^{\diamond}(p)\right]\right\}\left\{\left[p-c\left(i^{\diamond}\right)\right] \bar{q}^{\prime}\left(i^{\diamond}\right)-c^{\prime}\left(i^{\diamond}\right) \bar{q}\left(i^{\diamond}\right)\right\} g(p) \mathrm{d} p .
\end{aligned}
$$

The right-hand side of equation (A.1) can be written as

$$
\begin{aligned}
& \left\{\mathrm{E}\left\{u^{\prime}\left[\hat{\pi}^{\diamond}(\tilde{p})\right] \mid \tilde{p}>c\left(i^{\diamond}\right)\right\}-\mathrm{E}\left\{u^{\prime}\left[\hat{\pi}^{\diamond}(\tilde{p})\right]\right\}\right\}\left\{1-G\left[c\left(i^{\diamond}\right)\right]\right\} c^{\prime}\left(i^{\diamond}\right) \bar{q}\left(i^{\diamond}\right) \\
& -\operatorname{Cov}\left\{u^{\prime}\left[\hat{\pi}^{\diamond}(\tilde{p})\right], \max \left[\tilde{p}-c\left(i^{\diamond}\right), 0\right]\right\} \bar{q}^{\prime}\left(i^{\diamond}\right) .
\end{aligned}
$$

Since $\hat{\pi}^{\diamond}(p)=\max \left[p-c\left(i^{\diamond}\right), 0\right] \bar{q}\left(i^{\diamond}\right)-i^{\diamond}$, we have $\hat{\pi}^{\diamond}(p)=-i^{\diamond}$ for all $p \in\left[\underline{p}, c\left(i^{\diamond}\right)\right]$ and $\hat{\pi}^{\diamond}(p)=\left[p-c\left(i^{\diamond}\right)\right] \bar{q}\left(i^{\diamond}\right)-i^{\diamond}$ for all $p \in\left(c\left(i^{\diamond}\right), \bar{p}\right]$. It thus follows from risk aversion that $\mathrm{E}\left\{u^{\prime}\left[\hat{\pi}^{\diamond}(\tilde{p})\right] \mid \tilde{p}>c\left(i^{\diamond}\right)\right\}<\mathrm{E}\left\{u^{\prime}\left[\hat{\pi}^{\diamond}(\tilde{p})\right]\right\}$. Given that $0<G\left[c\left(i^{\diamond}\right)\right]<1$ and $c^{\prime}(i) \leq 0$, the first term of expression (A.2) is unambiguously positive.

Since $\hat{\pi}^{\diamond}(p)=\max \left[p-c\left(i^{\diamond}\right), 0\right] \bar{q}\left(i^{\diamond}\right)-i^{\diamond}$, we have $\hat{\pi}^{\diamond}(p)=-i^{\diamond}$ for all $p \in\left[\underline{p}, c\left(i^{\diamond}\right)\right]$ and $\hat{\pi}^{\diamond}(p)=\left[p-c\left(i^{\diamond}\right)\right] \bar{q}\left(i^{\diamond}\right)-i^{\diamond}$ for all $p \in\left(c\left(i^{\diamond}\right), \bar{p}\right]$. There must exist a unique point, $p_{0} \in\left(c\left(i^{\diamond}\right), \bar{p}\right)$, such that $u^{\prime}\left[\hat{\pi}^{\diamond}(p)\right]>(<) \mathrm{E}\left\{u^{\prime}\left[\hat{\pi}^{\diamond}(\tilde{p})\right]\right\}$ for all $p<(>) p_{0}$. We can write the second term of expression (A.2) as

$$
\begin{aligned}
\int_{c\left(i^{\diamond}\right)}^{\bar{p}}\left\{\mathrm{E}\left\{u^{\prime}\left[\hat{\pi}^{\diamond}(\tilde{p})\right]\right\}\right. & \left.-u^{\prime}\left[\hat{\pi}^{\diamond}(p)\right]\right\}\left(p-p_{0}\right) g(p) \mathrm{d} p \bar{q}^{\prime}\left(i^{\diamond}\right) \\
& +\int_{c\left(i^{\diamond}\right)}^{\bar{p}}\left\{\mathrm{E}\left\{u^{\prime}\left[\hat{\pi}^{\diamond}(\tilde{p})\right]\right\}-u^{\prime}\left[\hat{\pi}^{\diamond}(p)\right]\right\}\left[p_{0}-c\left(i^{\diamond}\right)\right] g(p) \mathrm{d} p \bar{q}^{\prime}\left(i^{\diamond}\right) .
\end{aligned}
$$


Since $\bar{q}^{\prime}(i) \geq 0$, the first term of expression (A.3) is unambiguously positive. The second term of expression (A.3) can be written as

$$
\left\{\mathrm{E}\left\{u^{\prime}\left[\hat{\pi}^{\diamond}(\tilde{p})\right]\right\}-\mathrm{E}\left\{u^{\prime}\left[\hat{\pi}^{\diamond}(\tilde{p})\right] \mid \tilde{p}>c\left(i^{\diamond}\right)\right\}\right\}\left[p_{0}-c\left(i^{\diamond}\right)\right]\left\{1-G\left[c\left(i^{\diamond}\right)\right]\right\} \bar{q}^{\prime}\left(i^{\diamond}\right)
$$

Since $\mathrm{E}\left\{u^{\prime}\left[\hat{\pi}^{\diamond}(\tilde{p})\right] \mid \tilde{p}>c\left(i^{\diamond}\right)\right\}<\mathrm{E}\left\{u^{\prime}\left[\hat{\pi}^{\diamond}(\tilde{p})\right]\right\} . p_{0}>c\left(i^{\diamond}\right), 0<G\left[c\left(i^{\diamond}\right)\right]<1$, and $\bar{q}^{\prime}(i) \geq 0$, this term is also unambiguously positive.

Since the right-hand side of equation (A.1) is positive and $\mathrm{E}\left\{u^{\prime}\left[\hat{\pi}^{\diamond}(\tilde{p})\right]\right\}>0$, inspection of equation (A.1) reveals that

$$
\int_{c\left(i^{\diamond}\right)}^{\bar{p}}\left\{\left[p-c\left(i^{\diamond}\right)\right] \bar{q}^{\prime}\left(i^{\diamond}\right)-c^{\prime}\left(i^{\diamond}\right) \bar{q}\left(i^{\diamond}\right)\right\} g(p) \mathrm{d} p-1>0
$$

It then follows from equation (6) and the second-order conditions for program (3) that $i^{*}>i^{\diamond}$.

\section{References}

Batra, RN and A Ullah (1974). Competitive firm and the theory of input demand under price uncertainty. Journal of Political Economy, 82, 537-548.

Broll, U and JE Wahl (1997). Export flexibility and hedging. Bulletin of Economic Research, 49, 205-211.

Carr, P and D Madan (2001). Optimal positioning in derivative securities. Quantitative Finance, 1, 19-37.

Chang, EC and KP Wong (2003). Cross-hedging with currency options and futures. Journal of Financial and Quantitative Analysis, 38, 555-574.

Chavas, J-P (1985). On the theory of the competitive firm under uncertainty when initial wealth is random. Southern Economic Journal, 51, 818-827.

Danthine, J-P (1978). Information, futures prices, and stabilizing speculation. Journal of Economic Theory, 17, 79-98. 
Interaction between Abandonment Options and Exotic Hedging

Eldor, R and I Zilcha (1987). Discriminating monopoly, forward markets and international trade. International Economic Review, 28, 459-468.

Feder, G, RE Just and A Schmitz (1980). Futures markets and the theory of the firm under price uncertainty. Quarterly Journal of Economics, 94, 317-328.

Froot, KA, DS Scharfstein and JC Stein (1993). Risk management: Coordinating corporate investment and financing policies. Journal of Finance, 48, 1629-1658.

Holthausen, DM (1979). Hedging and the competitive firm under price uncertainty. American Economic Review, 69, 989-995.

McDonald, RL (2003). Derivatives Markets. Boston: Addison Wesley.

McDonald, RL and DR Siegel (1985). Investment and the valuation of firms when there is an option to shut down. International Economic Review, 26, 331-349.

Mossin, J (1968). Aspects of rational insurance purchasing. Journal of Political Economy, $76,553-68$.

Myers, SC and S Majd (1990). Abandonment value and project life. In FJ Fabozzi (ed.), Advances in Futures and Options Research, Vol. 4. Greenwich: JAI Press.

Robichek, AA and JC Van Horne (1967). Abandonment value in capital budgeting. Journal of Finance, 22, 577-590.

Ross, SA, RW Westerfield and JF Jaffe (2005). Corporate Finance. Seventh edition. New York: McGraw-Hill/Irwin.

Sandmo, A (1971). On the theory of the competitive firm under price uncertainty. American Economic Review, 61, 65-73.

Smith, CW and RM Stulz (1985). The determinants of firms' hedging policies. Journal of Financial and Quantitative Analysis, 20, 391-405.

Stulz, RM (1984). Optimal hedging policies. Journal of Financial and Quantitative Analysis, 19, 127-140.

Stulz, RM (1990). Managerial discretion and optimal financial policies. Journal of Financial 
Economics, 26, 3-27.

Triantis, A and A Borison (2001). Real options: State of the practice. Journal of Applied Corporate Finance, 14, 8-24.

Tufano, P (1996). Who manages risk? An empirical examination of risk management practices in the gold mining industry. Journal of Finance, 51, 1097-1137.

Ware, R and R Winter (1988). Forward markets, currency options and the hedging of foreign exchange risk. Journal of International Economics, 25, 291-302.

Wong, KP (1996). Background risk and the theory of the competitive firm under uncertainty. Bulletin of Economic Research, 48, 241-251.

Wong, KP (2001). Currency hedging for export-flexible firms. International Economic Journal, 15, 165-174.

Wong, KP (2003). Export flexibility and currency hedging. International Economic Review, $44,1295-1312$.

Wong, KP (2004). The effects of abandonment options on operating leverage and forward hedging. International Review of Economics and Finance, forthcoming. 